\title{
MODELLING AND NEUTRON DIFFRACTION MEASUREMENT OF STRESSES IN SPRAYED TBCS
}

\author{
J.A. Thompson ${ }^{1}$, J. Matejicek ${ }^{2}$ \& T.W. Clyne ${ }^{1}$
}

1 Department of Materials Science \& Metallurgy

University of Cambridge, Pembroke St,

Cambridge, CB2 3QZ, UK.

\section{Abstract}

Thick TBC deposits have been deposited onto mild steel substrates. A CoNiCrAlY bond coat was applied by vacuum plasma spraying (VPS), while a $\mathrm{ZrO}_{2}-8 \mathrm{wt} \%$ top coat was deposited by air plasma spraying (APS). An in-situ curvature monitoring technique was used, in conjunction with thermal histories and deposit and substrate properties, to assist in the running of an existing numerical process model for the prediction of residual stresses in thermally sprayed coatings. Neutron diffraction experiments were performed independently on the same samples, in order to obtain the through thickness stress profiles. The agreement between the results obtained via these two techniques was excellent.

\section{Introduction}

With current superalloy technology rapidly approaching its theoretical limiting temperature, TBCs are now considered essential for raising the operating temperature of the next generation of aerospace engines $(1,2)$. A coating $250 \mu \mathrm{m}$ in thickness can raise the maximum engine temperature by about $100^{\circ} \mathrm{C}(3)$, an increase which represents significant savings in terms of cooling air and fuel reduction. Thermal spraying of such coatings results in a ceramic deposit of low thermal conductivity(4) and stiffness(5). Current procedures involve zirconia containing $6-8 w t \% \quad \mathrm{Y}_{2} \mathrm{O}_{3}$ being sprayed in air, after deposition of a vacuum plasma sprayed bond coat. The latter, commonly a CoNiCrAlY alloy, provides a dense active barrier to substrate oxidation, in addition to the rough surface necessary for improved bonding of the ceramic top coat(6).

\section{Experimental Methods}

\section{Plasma Spraying}

The powder composistions sprayed are given in Table I.

Vacuum plasma spraying was performed using a Plasma Technik
2 Department of Materials Science \& Engineering State University of New York, Stony Brook, NY 11794-2275, USA.

AG VPS system. The spray parameters are given in Table II. Air plasma spraying of the partially stabilised zirconia top coat could be carried out in the VPS chamber by operating the plasma gun without prior evacuation of the chamber. Mild steel was used for the substrate because it is very suitable for systematic neutron diffraction measurements, being virtually free of the complications which arise in many alloys during heat treatments as a result of changes in phase constitution.

The samples deposited are described in Table III

Table II: Plasma spray parameters for bond coat and top coat powder deposition.

\begin{tabular}{|c|c|c|}
\hline Material & CoNiCrAlY & $\begin{array}{c}\text { Zirconia - } \\
8 \text { wt \% } \mathrm{Y}_{2} \mathrm{O}_{3}\end{array}$ \\
\hline \hline Spray type & VPS & APS \\
\hline Spray distance (mm) & 270 & 120 \\
\hline Arc current (A) & 500 & 500 \\
\hline Voltage (V) & 55 & $60-70$ \\
\hline Ar flow rate (SLPM) & 50 & 80 \\
\hline H2 flow rate (SLPM) & 10 & 18 \\
\hline Gun speed (mm s') & 85 & 50 \\
\hline Chamber pressure & 200 mbar & atmospheric \\
\hline $\begin{array}{c}\text { Nozzle diameter } \\
\text { (mm) }\end{array}$ & 8 & 8 \\
\hline
\end{tabular}

Table III Specimen ID table

\begin{tabular}{|c|c|c|c|}
\hline Sample ID & $\begin{array}{c}\text { Substrate } \\
\text { thickness } \\
(\mathrm{mm})\end{array}$ & $\begin{array}{c}\text { Bond Coat } \\
\text { thickness } \\
(\mathrm{mm})\end{array}$ & $\begin{array}{c}\text { Top Coat } \\
\text { thickness } \\
(\mathrm{mm})\end{array}$ \\
\hline \hline B1 & 6.35 & 1.2 & - \\
\hline B2 & 6.35 & 0.8 & 2.07 \\
\hline B4 & 2.00 & 1.2 & - \\
\hline B5 & 2.00 & 0.8 & 1.43 \\
\hline
\end{tabular}

Table I: Composition (by weight) of powders for plasma spraying.

\begin{tabular}{|c|c|c|c|c|c|c|c|c|}
\hline Powder details & \multicolumn{7}{|c|}{ Content by weight \%. } \\
\hline \hline Coating Type & Material & $\mathrm{Ni}$ & $\mathrm{Co}$ & $\mathrm{Cr}$ & $\mathrm{Al}$ & $\mathrm{Y}$ & $\mathrm{ZrO}_{2}$ & $\mathrm{Y}_{2} \mathrm{O}_{3}$ \\
\hline bond coat & CoNiCrAIY & 32 & bal & 21 & 8 & 0.5 & - & - \\
\hline top coat & PSZ & - & - & - & - & - & bal & 8 \\
\hline
\end{tabular}




\section{Diffraction techniques}

The emergence in recent years of neutron diffraction as a viable technique has opened up the possibility of obtaining accurate stress profiles through the thickness of thermally sprayed samples, due to the much greater penetration depth of neutrons, compared to that of traditional X-rays $(7,8)$. In this sudy, neutron diffraction experiments were performed by J. Matejicek at the NIST facility, Gaithersburg, USA.

Table IV: Data used in the neutron diffraction analysis performed on TBC samples.

\begin{tabular}{|c|c|c|c|c|}
\hline Material & $\begin{array}{c}h k l \text { peak } \\
\text { analysed }\end{array}$ & $\begin{array}{c}\text { d spacing } \\
(\mathrm{nm})\end{array}$ & $\mathrm{E}(\mathrm{GPa})$ & $\begin{array}{c}\text { Poisson's } \\
\text { ratio }\end{array}$ \\
\hline \hline $\mathrm{Fe}$ & 110 & 0.2033 & 216 & 0.28 \\
\hline $\mathrm{CoNiCrAlY}$ & $111\left(\gamma^{\prime}\right)$ & 0.2076 & 233 & 0.29 \\
\hline $\mathrm{ZrO}_{2}$ & 112 & 0.2101 & 200 & 0.30 \\
\hline
\end{tabular}

Curvature based methods

Evaluation of curvature data is a potentially powerful method for the determination of residual stress and has been used with success in the past(9). However, care must be taken when employing this technique, particularly with regard to the interpretation of data.

In this study, the curvature is recorded continuously, via a video camera mounted alongside the spray chamber (Figure 1). The defection of the free end of the sample is recorded and converted to a curvature, since the length of the deflecting strip is known. This provides a powerful means of validation for the numerical process model described below, since the curvature history recorded during spraying of the coating can be easily compared with that predicted by the process model. The thermal history during spraying is also recorded, via a thermocouple spot welded to the rear face of the sample.

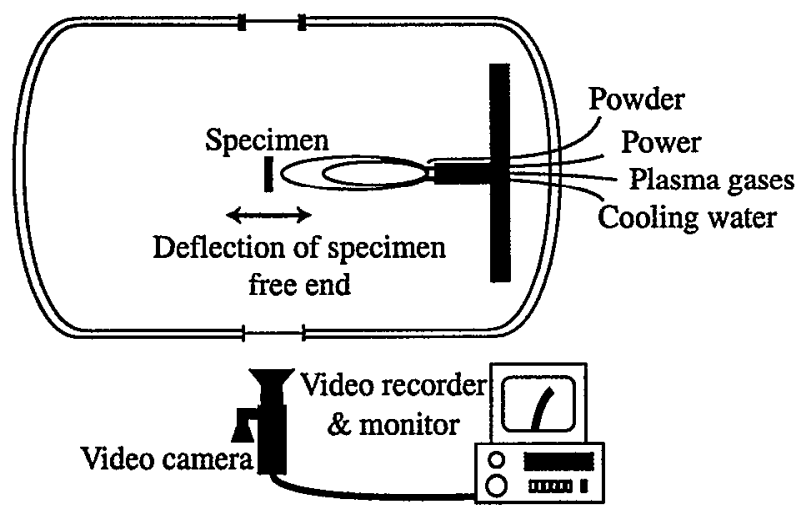

Figure 1: Arrangement of apparatus for in situ curvature monitoring.

\section{Substrate Characterisation}

The residual stress levels in the substrate material were evaluated prior to spraying by neutron diffraction.

Due to the wide range of properties exhibited by mild steel, dependent upon the precise composition and manufacturing process, the yield stress and creep properties of the substrate material were evaluated experimentally. The substrate yield stress was measured as a function of temperature. Substrate creep data were obtained using a non-contacting laser scanning extensometry (Lasermike) technique(10). Creep tests were performed under conditions of constant load and the steady state creep rate fitted to the Norton creep law (Equation 1).

$$
\dot{\varepsilon}=A \sigma^{\mathrm{n}} \exp \left(\frac{-\mathrm{Q}}{\mathrm{RT}}\right)
$$

Equation 1

where $A$ is the pre-exponential constant, $\sigma$ is the applied stress, $\mathrm{n}$ is the stress exponent for creep, $\mathrm{Q}$ is the activation energy for creep, $R$ is the molar gas constant and $T$ is the absolute temperature.

\section{Numerical modelling}

An existing numerical model(11-14) has been used in this study. The main points and assumptions behind this model can be summarised as follows:

i.) Heat flow is assumed to be one dimensional, through the thickness of the sample. Gaussian distributions of heat and mass are assumed and the gun movement during spraying can be modelled as required.

ii.) An equal biaxial stress state is assumed in the sample and through-thickness stresses are taken as negligible. Mechanical bonding at the substrate / coating interface is assumed to be perfect.

iif.) Each incoming molten splat generates unbalanced stress (the quenching stress) upon arriving at the surface.

iv.) The stress calculation is based on the determination of a relaxed width for each element in a stack through the thickness of the modelling point, according to temperature and mechanical properties. All elements are then constrained to have the same relaxed width (obtained using a force balance) and are then allowed to adopt a constant strain gradient through the thickness (obtained using a moment balance).

The thermal and curvature histories can be outputted by the model and compared with those obtained experimentally. This provides dual validation of the model. Experimental curvature histories can only be obtained for thin substrates, since deflections are difficult to measure for thicker substrates.

However, if the quenching stress can be measured from the compared curvature histories for coatings on thin substrates, the stress predictions for coatings deposited on thick substrates should be valid.

\section{Results}

\section{Substrate Characterisation}

The initial substrate residual stress levels are shown in Figures $2 \& 3$. While the substrate stress levels are low in the case of the thin substrate, they are high for the thicker samples. It was therefore necessary to consider these residual stresses in the numerical simulations of stress development during spraying and subsequent cooling. 


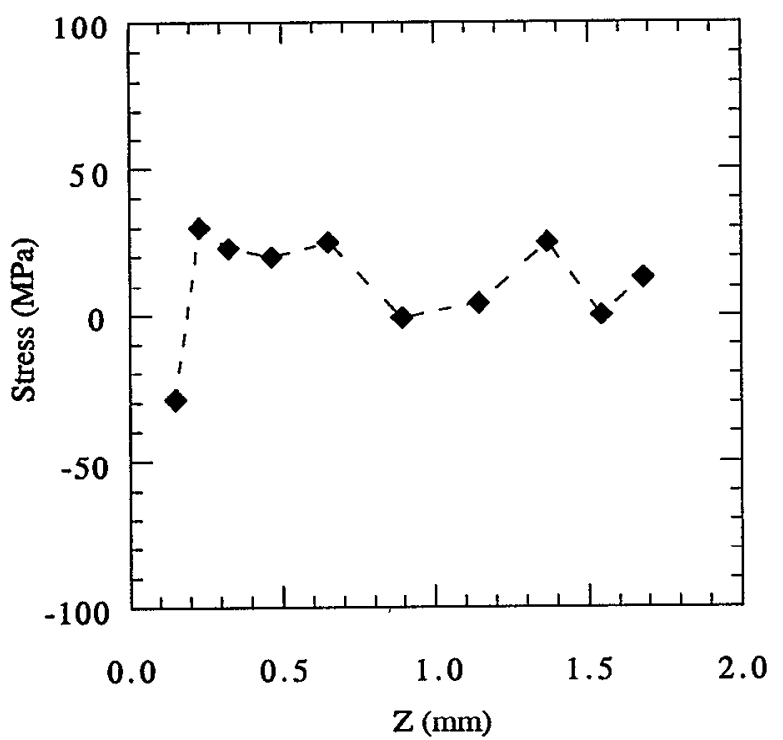

Figure 2: Residual stress state in thin steel substrate, measured by neutron diffraction.

The initial stress levels in the thick substrates were treated by altering the initial relaxed element width, such that, when constrained by the force and moment balances, the resulting stress state approximated to that measured by neutron diffraction. It is important that the changes in initial relaxed element width do not violate the conditions of the model. A stress distribution which is symmetrical about the neutral axis and exhibits equal amounts of tension and compression will satisfy the criteria of the model, such that the associated curvature is equal to zero (Figure 4).

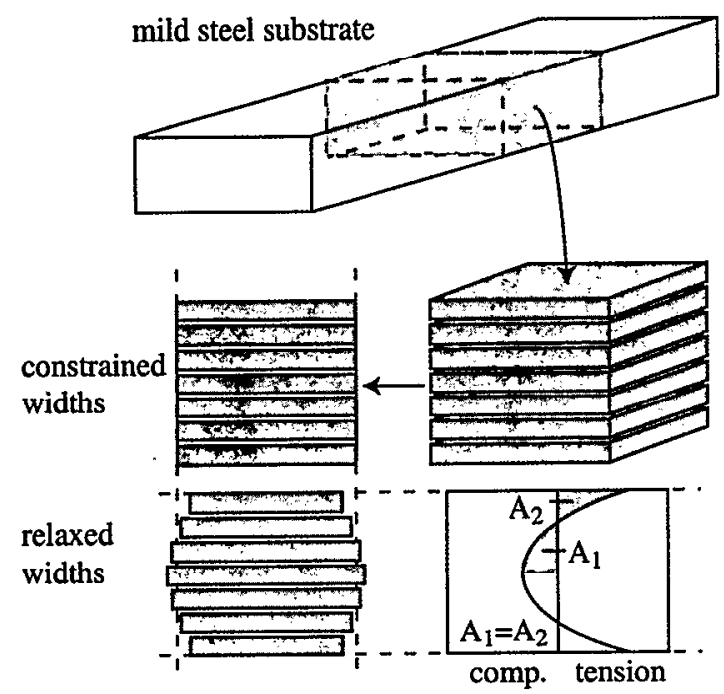

Figure 4: Schematic representation of the way in which the initial substrate residual stress state is treated by the numerical model.

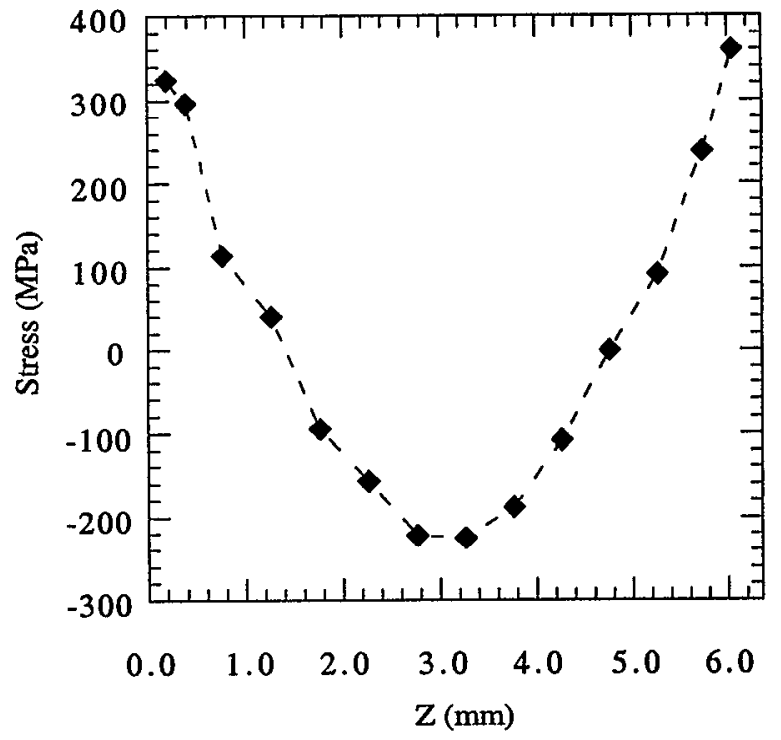

Figure 3: Residual stress state in thick steel substrate, measured by neutron diffraction.

The measured yield stress of the mild steel substrate is shown as a function of temperature in Figure 5 . It is clear that, at the deposition temperature, the yield stress of the substrate material is significantly reduced. In addition, the substrate will undergo significant stress relaxation by creep processes at such temperatures. The creep data are summarised in Table V. This will result in non-elastic behaviour of the substrate during processing. It is important that this be accurately simulated in the residual stress calculations.

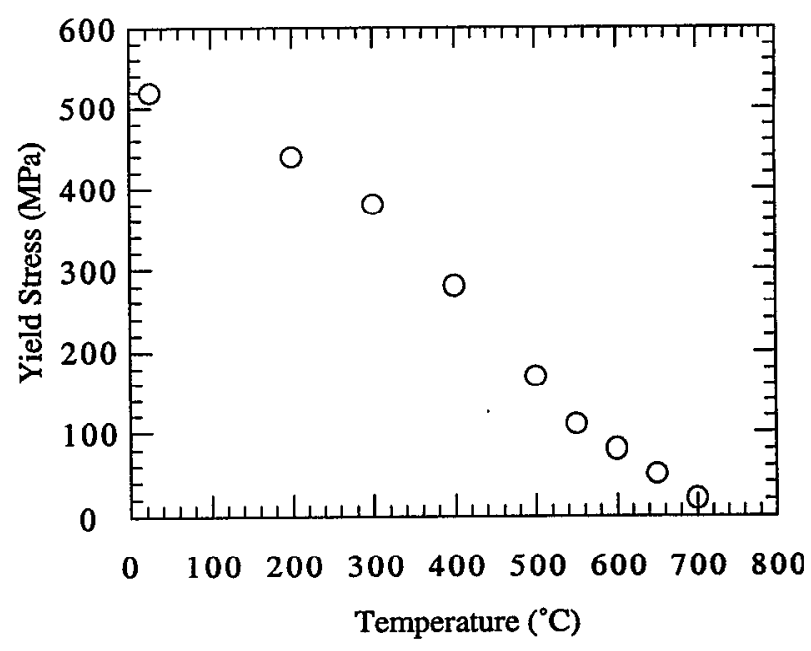

Figure 5: Variation of mild steel substrate yield stress with temperature. 
Table V: Summary of mild steel substrate yield and creep data.

\begin{tabular}{|c|c|c|c|c|c|c|c|c|c|}
\hline \multicolumn{10}{|c|}{ Yield Stress Data } \\
\hline $\mathrm{T}\left({ }^{\circ} \mathrm{C}\right)$ & $\overline{25}$ & 200 & 300 & 400 & 500 & 550 & 600 & 650 & 700 \\
\hline$\sigma_{\mathrm{y}}(\mathrm{MPa})$ & 520 & 440 & 380 & 280 & 170 & 110 & 80 & 50 & 20 \\
\hline \multicolumn{10}{|c|}{ Creep Data } \\
\hline \multicolumn{4}{|c|}{$\mathrm{n}$} & & \multicolumn{5}{|c|}{$\overline{3}$} \\
\hline \multicolumn{4}{|c|}{$\mathrm{Q}\left(\mathrm{kJ} \mathrm{mol}^{-1}\right)$} & & \multicolumn{5}{|c|}{400} \\
\hline \multicolumn{4}{|c|}{$\mathrm{A}\left(\mathrm{s}^{-1} \mathrm{~Pa}^{-\mathrm{n}}\right)$} & & \multicolumn{5}{|c|}{$4.7 \times 10^{-5}$} \\
\hline
\end{tabular}

\section{Numerical Modelling}

The input data for the numerical model are summarised in Table VI

The effect of creep on the predicted curvature history is significant. Figure 6 shows the experimental curvature history during deposition and subsequent cooling for sample B4. Figure 7 shows the predicted curvature histories for the same spray run, with and without creep included in the simulation.

The effect of creep is particularly clear during the first pass of the gun, where the increase in curvature is underpredicted when creep is neglected. The effect is most apparent here because the flexural stiffness of the beam is low (the sample is thin and predominantly made from the rapidly creeping substrate material, due to the low coating thickness at this time). During subsequent passes, the thickness of the substrate / coating sample increases, raising the flexural stiffness. In addition, the greater creep resistance of the CoNiCrAlY coating, in comparison with that of the substrate, lowers the specimen deflection during later passes of the gun.

Figures $8 \& 9$ show a comparison between predicted and measured temperature profiles during bond coat and top coat deposition (sample B5). It can be seen that the agreement is good. This is also the case in Figures $10 \& 11$, which compare the experimental curvature output with that predicted by the model. Both plots provide a means of validation for the model. Further compelling evidence is to be found in Figures 12-15, which show comparisons between residual stress levels obtained by neutron diffraction and those predicted by the model. Agreement is in general very good.
Table VI: Numerical modelling input data(15).

\begin{tabular}{|c|c|c|c|}
\hline Property & CoNiCrAlY & $\begin{array}{c}\mathrm{ZrO}_{2} 8 \mathrm{wt} \% \\
\mathrm{Y}_{2} \mathrm{O}_{3}\end{array}$ & mild steel \\
\hline $\begin{array}{c}\text { Thermal } \\
\text { conductivity } \\
\left(\mathrm{W} \mathrm{m}^{-1} \mathrm{~K}^{-1}\right)\end{array}$ & $\begin{array}{c}12.0(293 \mathrm{~K}) \\
20.0 \\
(1000 \mathrm{~K})\end{array}$ & $\begin{array}{c}0.72(283 \mathrm{~K}) \\
2.164 \\
(1352 \mathrm{~K})\end{array}$ & $\begin{array}{c}49.6(300 \mathrm{~K}) \\
40.0(673 \mathrm{~K}) \\
23.6 \\
(1073 \mathrm{~K})\end{array}$ \\
\hline $\begin{array}{l}\text { Specific heat } \\
\text { capacity } \\
\left(\mathrm{J} \mathrm{kg}^{-1} \mathrm{~K}^{-1}\right)\end{array}$ & 350.0 & $\begin{array}{l}480(293 \mathrm{~K}) \\
610(873 \mathrm{~K})\end{array}$ & $\begin{array}{l}483(293 K) \\
596(873 K)\end{array}$ \\
\hline $\begin{array}{l}\text { Latent heat of } \\
\text { fusion } \\
\left(\mathrm{kJ} \mathrm{kg}^{-1}\right)\end{array}$ & 300 & 300 & - \\
\hline Melting point $(\mathrm{K})$ & 1673 & 3080 & - \\
\hline $\begin{array}{c}\text { Droplet } \\
\text { temperature }(\mathbf{K})\end{array}$ & 1673 & 3080 & - \\
\hline Density $\left(\mathrm{kg} \mathrm{m}^{-3}\right)$ & 7.00 & 5.28 & 7.85 \\
\hline $\begin{array}{l}\text { Thermal } \\
\text { expansivity } \\
\times 10^{6}\left(\mathrm{~K}^{-1}\right)\end{array}$ & $\mid \begin{array}{ll}13.0 & (298 K) \\
18.5 & (773 K) \\
20.1 & (873 K) \\
21.5 & (973 K) \\
\end{array}$ & $\begin{array}{c}10.5(283 \mathrm{~K}) \\
11.5(811 \mathrm{~K}) \\
11.8 \\
(1144 \mathrm{~K})\end{array}$ & \begin{tabular}{|l}
$12.0(298 \mathrm{~K})$ \\
$13.3(573 \mathrm{~K})$ \\
$15.9(573 \mathrm{~K})$
\end{tabular} \\
\hline $\begin{array}{c}\text { Young's modulus } \\
(\mathrm{GPa})\end{array}$ & $\begin{array}{l}125(293 \mathrm{~K}) \\
85(1073 \mathrm{~K})\end{array}$ & $\begin{array}{l}10.0(293 \mathrm{~K}) \\
5.0(1293 \mathrm{~K})\end{array}$ & \begin{tabular}{|c|}
$208(366 \mathrm{~K})$ \\
$186(590 \mathrm{~K})$ \\
117 \\
$(1033 \mathrm{~K})$ \\
\end{tabular} \\
\hline Poisson ratio & 0.30 & 0.30 & 0.30 \\
\hline $\begin{array}{l}\text { Elastic Limit } \\
\qquad(\mathrm{MPa})\end{array}$ & $\infty$ & $\infty$ & $\begin{array}{l}520(293 \mathrm{~K}) \\
170(773 \mathrm{~K}) \\
70(873 \mathrm{~K}) \\
20(973 \mathrm{~K})\end{array}$ \\
\hline $\begin{array}{c}\text { Quenching Stress } \\
(\mathrm{MPa})\end{array}$ & $\begin{array}{c}130 \\
\left(\mathrm{~T}_{\mathrm{S}}=\right. \\
\left.550^{\circ} \mathrm{C}\right)\end{array}$ & 5.0 & - \\
\hline $\begin{array}{c}\text { Creep parameters } \\
n \\
\mathrm{Q}\left(\mathrm{kJ} \mathrm{mol}^{-1}\right) \\
\mathrm{A}\left(\mathrm{s}^{-1} \mathrm{~Pa}^{-\mathrm{n}}\right)\end{array}$ & $\begin{array}{c}2.9 \\
361 \\
4.6 \times 10^{-10} \\
\end{array}$ & $\begin{array}{l}- \\
- \\
-\end{array}$ & $\begin{array}{c}3 \\
400 \\
4.7 \times 10^{-5} \\
\end{array}$ \\
\hline
\end{tabular}




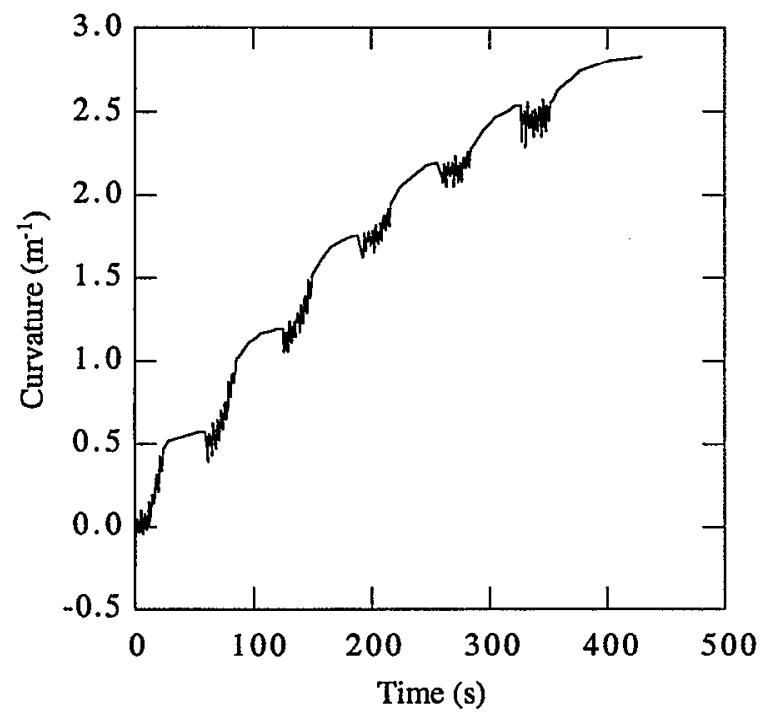

Figure 6: Experimental curvature history during spraying of CoNiCrAlY bond coat onto a thin mild steel substrate (sample B4).

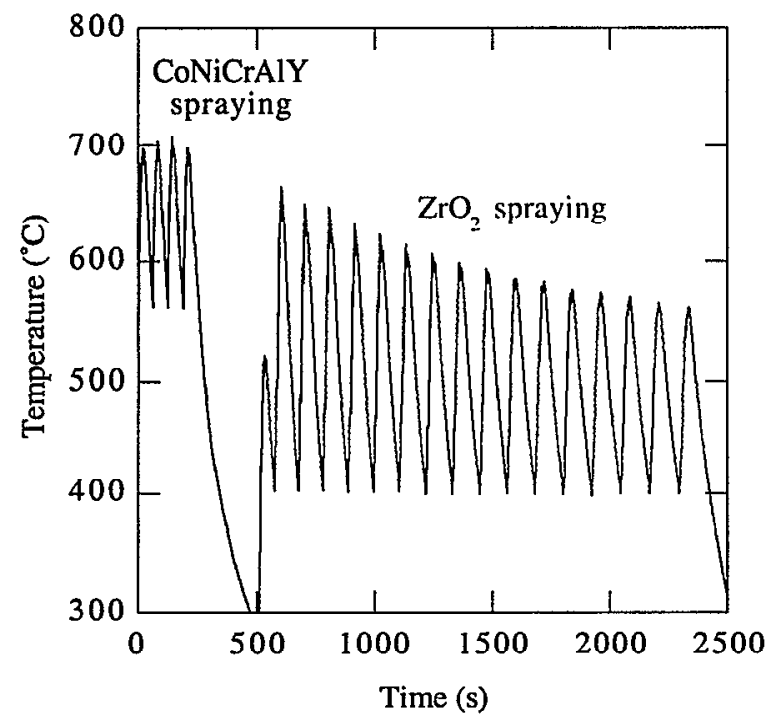

Figure 8: $\quad$ Experimental temperature history for sample B5.

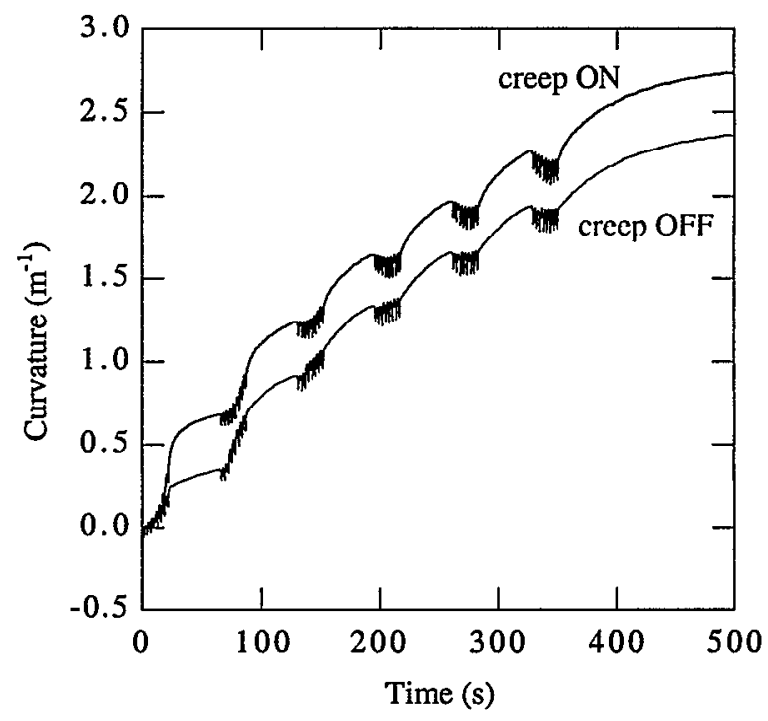

Figure 7: Predicted curvature histories for CoNiCrAlY deposition onto a thin mild steel substrate (sample B4), showing the effect of creep being incorporated in the calculation.

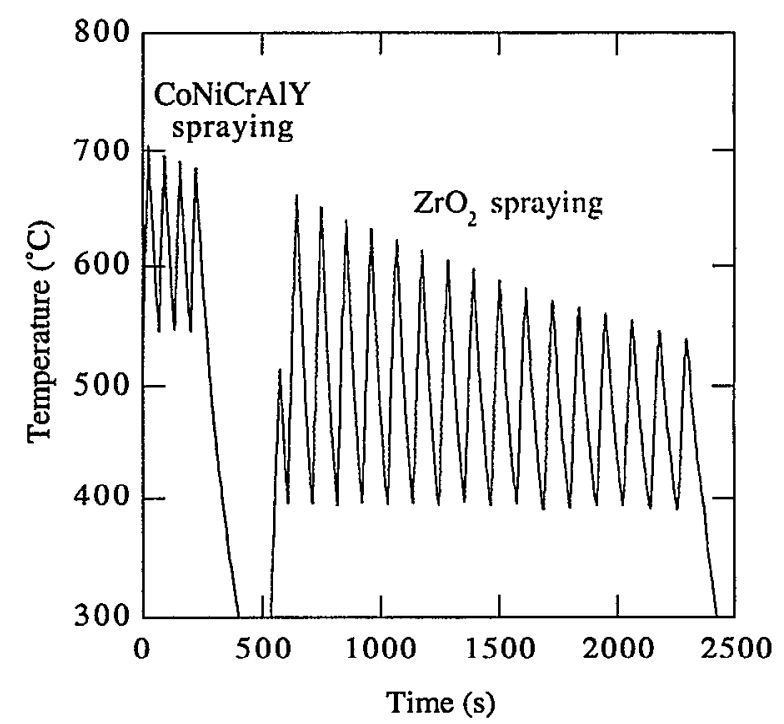

Figure 9: $\quad$ Predicted temperature history for sample B5. 


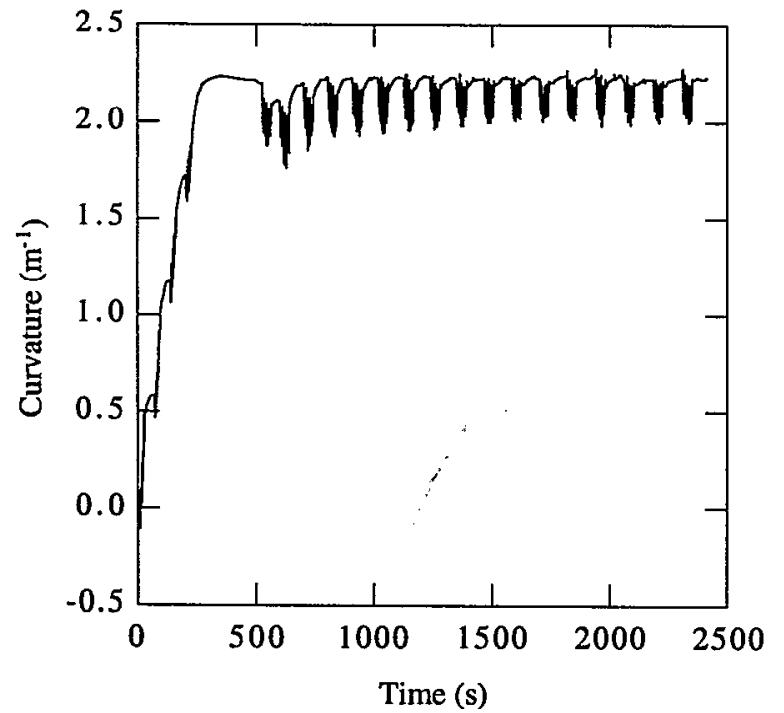

Figure 10: Experimental curvature history during spraying of sample B5.

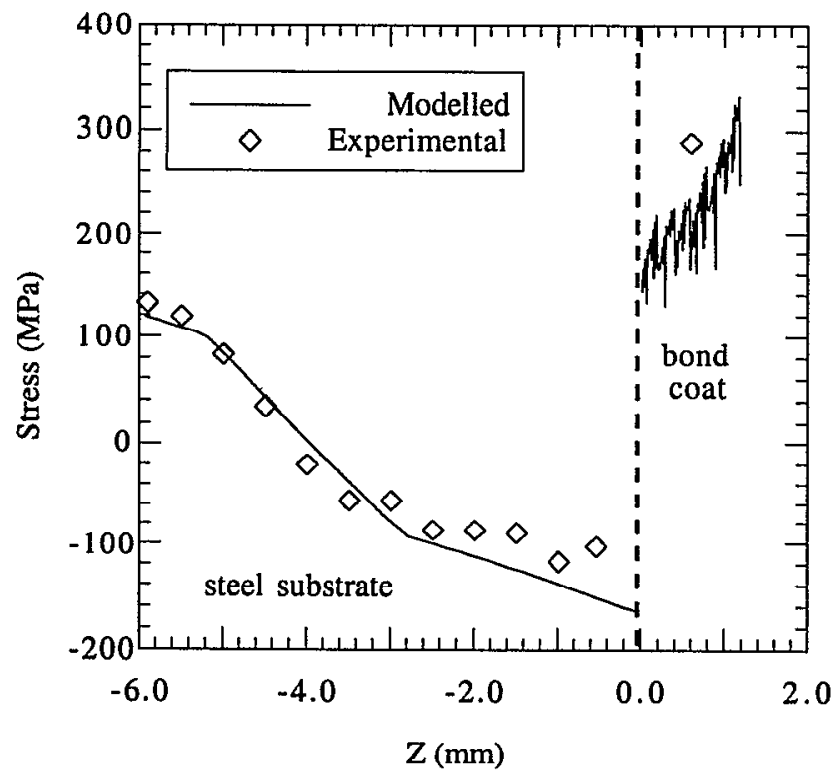

Figure 12: Residual stress comparison for sample B1 .

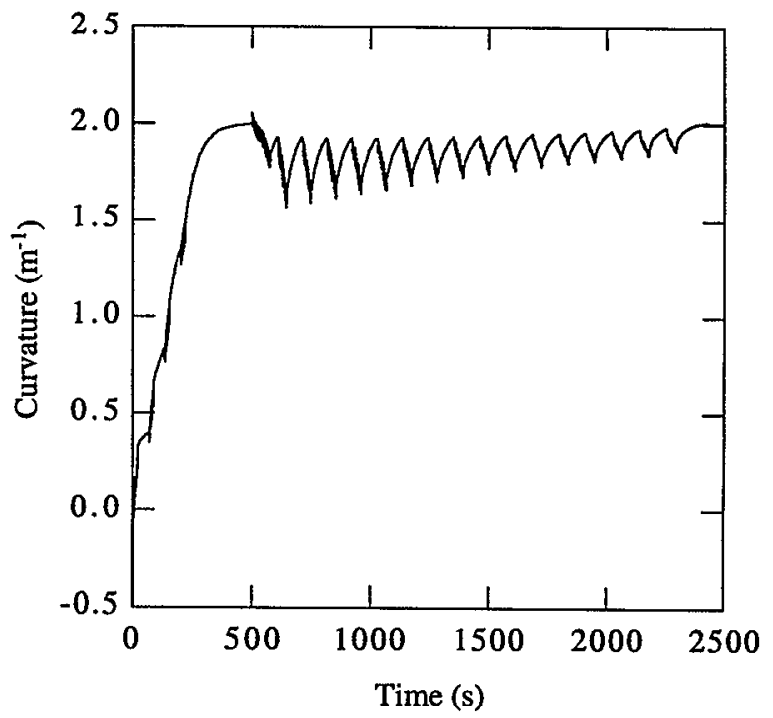

Figure 11: Predicted curvature history during spraying of sample B5.

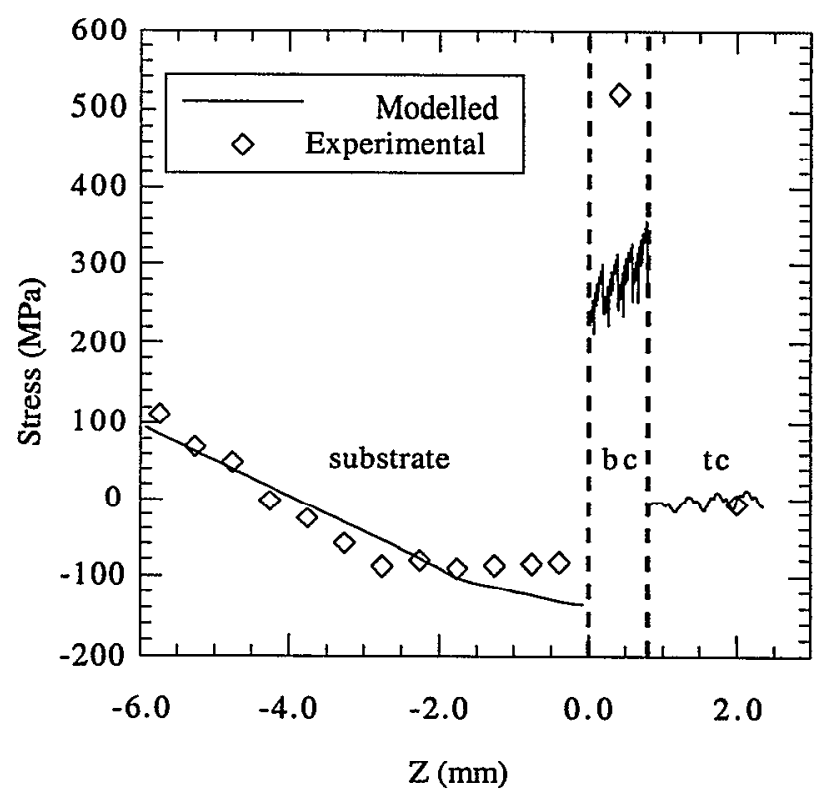

Figure 13: Residual stress comparison for sample B2. 


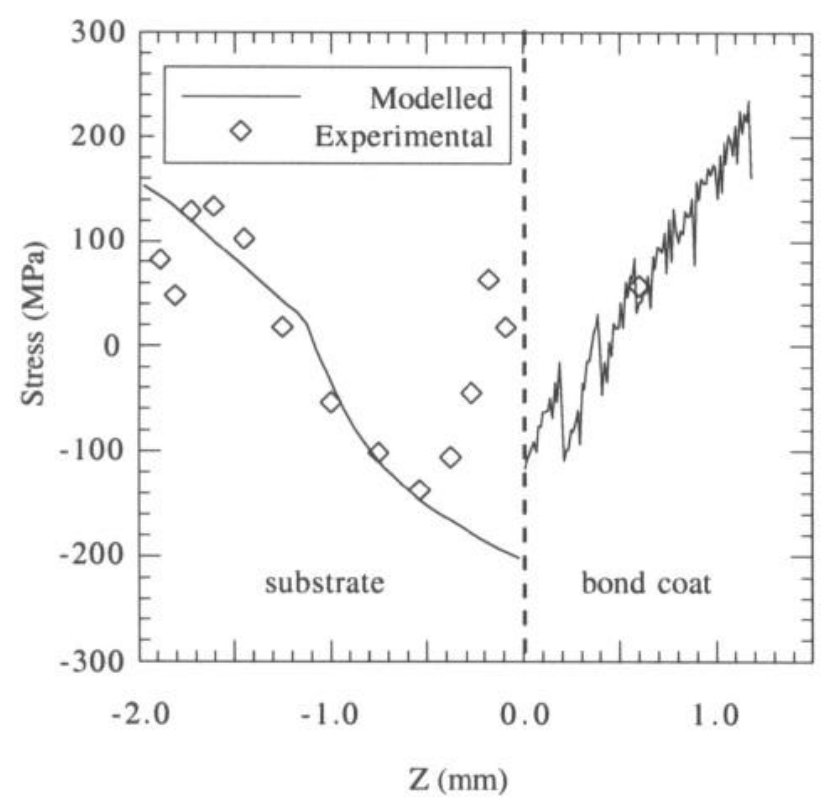

Figure 14: Residual stress comparison for sample B4.

Unfortunately, due to the requirements in terms of gauge volume needed to give acceptable count rates during neutron diffraction, through-thickness profiling was not possible in the bond coat (despite the artificially high thicknesses deposited) or in the zirconia.

While substrate stress levels predicted for the case of the thick steel substrates (B1/2) are in excellent agreement with experiment, there is a discrepancy in the case of the thin substrates (B4/5). In the regions close to the substrate free surface and the substrate / bond coat interface, the neutron diffraction data indicate a reduction in the magnitude of the measured stress. This aspect of the stress distribution is not predicted by the numerical model.

Microstructural investigation (Figure 16) demonstrates that there is no significant change in the grain structure in these regions. Therefore recrystallisation of the substrate can be ruled out as a possible explanation for this discrepancy. It seems more likely that the treatment of edge effects during the analysis of the neutron diffraction data may be responsible for the deviation from of the predicted stress distribution. However, it is not clear why this behaviour was seen for the thin substrates, but not in samples deposited on thicker substrates.

The stress distribution in the as-sprayed bond coat shows good agreement with the model prediction (samples B 1/4). However, after the top coat was deposited, the model gives a lower average stress in the bond coat than that measured by neutron diffraction. This may be due to bond coat creep having a stronger effect than that simulated in the model. (Although the effects of CoNiCrAlY creep are included in the model, the creep rates assumed are steady state values. It may be the case that creep is occurring faster in the initial stages - i.e. that primary creep is significant.)

Also of interest is the predicted stress gradient through the bond coat. Coatings on both thin and thick substrates exhibit

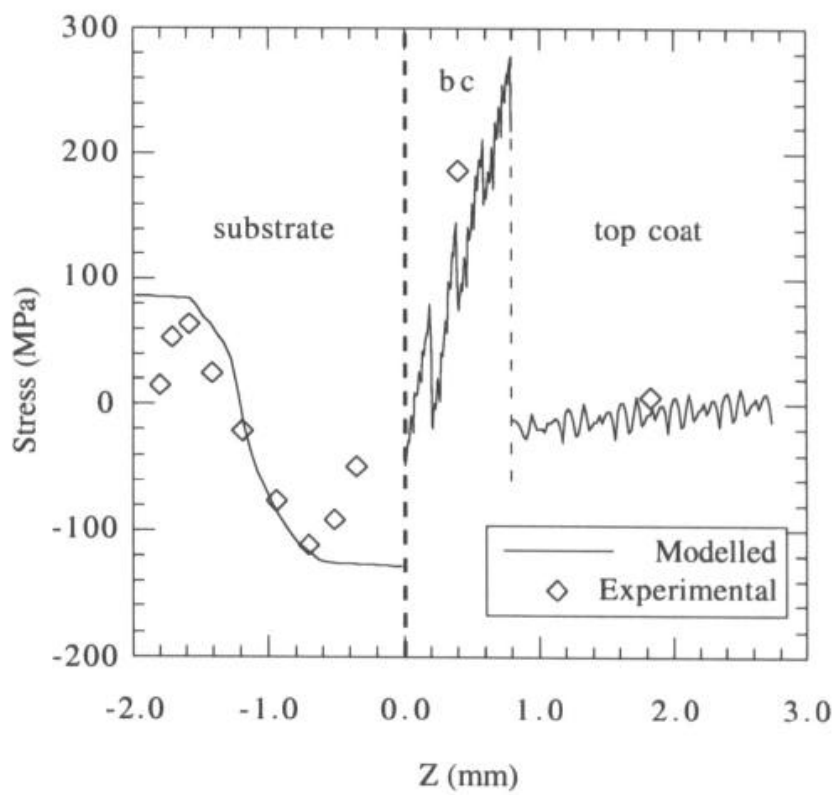

Figure 15: Residual stress comparison for sample B5.

a pronounced stress gradient. However, the effect is stronger for thin substrates. This can be understood by considering the deposition process (Figure 17). (1) A thin layer impinges on substrate and contracts on cooling (2) to the substrate temperature. Force and moment balances are applied $(3,4)$ to give the stress state and curvature. A second layer then impinges, freezes and cools to the substrate temperature $(5,6)$. New relaxed widths are calculated (7), before the force and moment balances are reapplied $(8,9)$. This process is repeated until the coating reaches the desired thickness. A positive stress gradient in the coating arises as a result of the incremental deposition process, demonstrating the importance of the simulation occurring progressively in order to accurately represent the true physical effects. Where the substrate is thicker, the change in initial element width with subsequent layer deposition will be smaller (due to the increase in sample flexural stiffness) and the coating stress gradient is reduced.

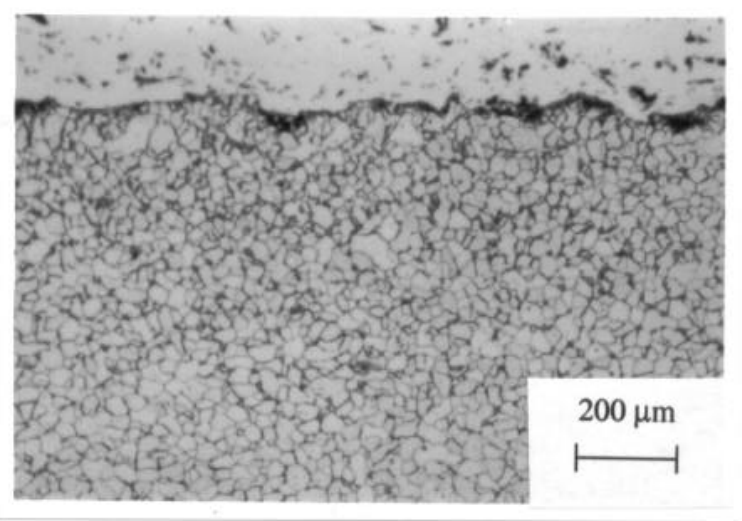

Figure 16: Optical micrograph of mild steel substrate / bond coat interface. Note that there is no change in substrate grain size in the region near the interface. 

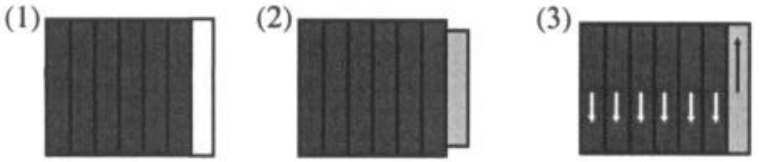

(4)

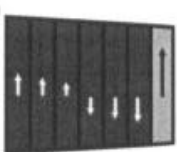

(5)
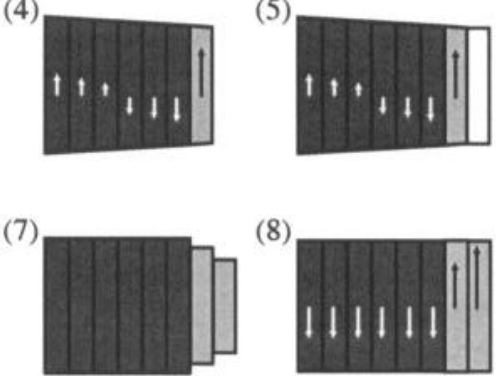

(8)

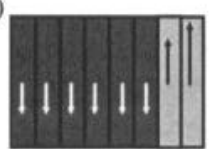

(6)

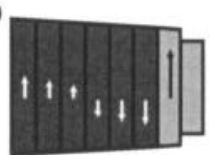

(9)

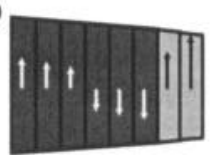

Figure 17: Schematic representation of stress development during spraying.

The top coat stresses are low in all cases. This is due to the low stiffness of the APS zirconia coating, which arises as a result of the dense network of microcracks which form during quenching of incoming zirconia splats to the substrate temperature (Figure 18). Further evidence of low top coat stresses can be found in the experimental curvature history during top coat deposition (Figure 10). The overall changes in curvature during top coat spraying are small, indicating low stresses.

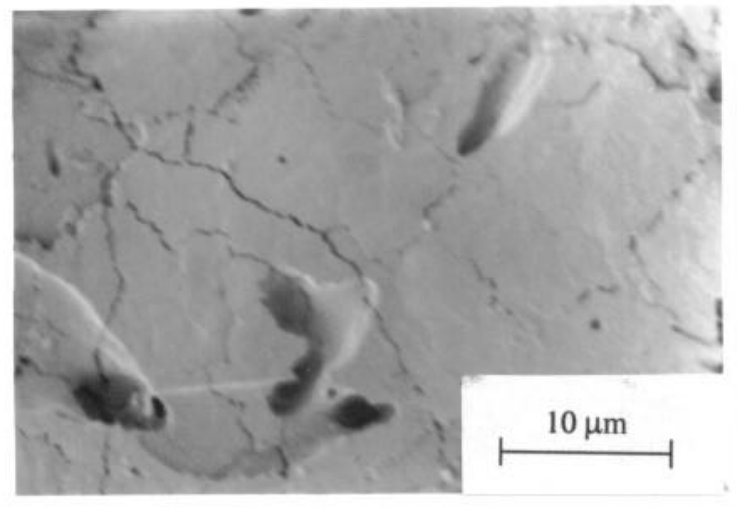

Figure 18: SEM micrograph of the top surface of an as-sprayed $\mathrm{ZrO}_{2} 8 \mathrm{wt} \% \mathrm{Y}_{2} \mathrm{O}_{3}$ coating, showing the presence of microcracks which contribute to the low coating stiffness.

\section{Conclusions}

These results show the power of the numerical process model to predict residual stresses with a high level of reliability, given the correct input data for the process. Samples were prepared on both thick and thin substrates and the model predictions were accurate in both cases, proving that the quenching stress values obtained for spraying onto thin substrates were applicable for the case of the thicker substrate.

Development of residual stresses in service is of considerable importance when considering the possibility of coating failure,

usually by spallation of the top coat. This study provides useful confirmation that the modelling assumptions are valid. The same calculation process (relaxed width method) can be used to simulate the changes in residual stress during service.

However, the availability of suitable material data is an important issue. Given these data, the numerical model can provide a useful insight into the relative importance of various phenomena (e.g. bond coat creep, top coat sintering), which might contribute to eventual coating spallation.

\section{References}

1. A. Bennett, "Properties of Thermal Barrier Coatings", Mater. Sci. Technol, 2 (1986), 257-261

2. A. Bennett, F. Toriz and A. Thakker, "A Philosophy for Thermal Barrier Coating Design and its Corroboration by $10000 \mathrm{~h}$ Service Experience on RB211 Nozzle Guide Vanes", Surface \& Coatings Technology, 32 (1987), 359-375.

3. H. E. Eaton and R. C. Novak, "Sintering Studies of Plasma Sprayed Zirconia", Surf. Coat. Technol., 32 (1987), 227-236.

4. T. Taylor, "Thermal Propertries and Microstructure of Two Thermal Barrier Coatings", Surface \& Coatings Technology, 54/55 (1992), 53-57.

5. P. Scardi, M. Leoni and L. Bertamini, "Residual Stresses in Plasma Sprayed Partially Stabilised Zirconia TBCs Influence of the Deposition Temperature", Thin Sol. films, 278 (1996), 96-103.

6. G. W. Meetham, "Coating Requirements in Gas Turbine Engines", J. Vac. Sci. Technol, A3 (1985), 2509-2515.

7. O. Kesler et al., "Measurement of Residual Stress in Plasma-Sprayed Metallic, Ceramic and Composite Coatings", Mat. Sci. \& Eng., (1998),

8. J. Matejicek et al., "Quenching, Thermal and Residual Stress in Plasma Sprayed Deposits: NiCrAlY and YSZ Coatings", Acta Mater, 47(2) (1999), 607-617.

9. S. Kuroda, T. Fukushima and S. Kitahara, "Generation Mechanisms of Residual-Stresses in Plasma-Sprayed Coatings", Vacuum, 41(224) (1990), 1297-1299.

10. Y. C. Tsui, J. A. Thompson and T. W. Clyne, "The Effect of Bond Coat Creep on Residual Stresses and Debonding in Plasma Sprayed Thermal Barrier Systems", in Thermal Spray: Meeting the Challenges of the 21st Century. Proceedings of the 15th Int. Thermal Spray Conf. (1998), Nice, France, C. Coddet (Ed.) Vol. 2, ASM International, 1565-1570.

11. S. C. Gill and T. W. Clyne, "Stress Distributions and Material Response in Thermal Spraying of Metallic and Ceramic Deposits", Met. Trans., 21B (1990), 377-385.

12. S. C. Gill and T. W. Clyne, "The Effect of Substrate Temperature and Thickness on Residual Stresses in Plasma Sprayed Deposits during Thermal Spraying", in 
2nd European Conference on Advanced Materials and Processes, Euromat'91 (1992), Cambridge, UK, T. W. Clync and P. J. Withers (Eds.), Vol. 1, Institute of Materials, 289-297.

13. S. Gill and T. W. Clyne, "Thermomechanical Modelling of the Development of Residual Stress during Thermal Spraying", in 2nd Plasma Technik Symposium (1991), Lucerne, Switzerland, H. Eschenauer, P. Huber, A. R. Nicoll and S. Sandmeier (Eds.), Vol. 3, Plasma Technik, 227-238.

14. Y. C. Tsui, S. C. Gill and T. W. Clyne, "Simulation of the Effect of Creep on the Stress Fields during Thermal Spraying onto Titanium Substrates", Surf. Coat. Technol., 64 (1994), 61-68.

15. Y. C. Tsui, "Adhesion of Plasma Spraycd Coatings", (PhD Thesis, University of Cambridge, 1996), Pages. 